\title{
Can Environmental Governance Benefit from ICT-Social Capital Nexus in Civil Society?
}

\author{
Subas P. Dhakal \\ Institute for Sustainability and Technology Policy \\ Murdoch University, Western Australia \\ subasdhakal@gmail.com
}

\begin{abstract}
Although the potential of Information and Communication Technologies (ICT) to foster social capital in civil society has been duly acknowledged, few studies have empirically explored the ICT-social capital nexus in the context of community organizations. Huysman and Wulf (2004) consider the lack of interest in the area of 'ICT and social capital' as worrisome in today's increasingly network-centric society. Since the prospect of ICT furthering social capital is simply too significant to ignore, this paper responds to this gap by reporting on one aspect of a 2008 survey of environmental community organizations (ECOs) undertaken to develop a broader understanding of the linkages between organizational social capital and information and communication technologies in the Perth region of Western Australia. By exploring the trend of ICT uptake, pattern of intra-organizational as well as inter-organizational interactions, and the association between ICT uptake and organizational interactions, this paper critically engages in the 'ICT and social capital' debate and discusses the implications of ICT-social capital nexus in the context of environmental governance.
\end{abstract}

Keywords: Civil society, environmental governance, ICT, social capital

Acknowledgement: This research was conducted within the Australasian CRC for Interaction Design (ACID), which is established and supported under the Australian Government's Cooperative Research Centres Program. The author is thankful to Dr. Ian Barns and Dr. Ingrid Richardson of Murdoch University for their incessant guidance during the research and the leaders of Environmental Community Organizations in Perth who kindly participated in the survey.

\section{Introduction}

The potential of information and communication technologies (ICT) in transforming the ways civil society e.g. community organizations shape various societal outcomes, ranging from the recent political uprising in the Middle East (Dunn, 2011; Ritter \& Trechsel, 2011) to the protection of local environment (Hawken, 2007; Dhakal, 2008) has been increasingly recognised in recent years. Consequently, although community organizations are not recognized as leaders in adoption of ICT, policy level as well as pragmatic initiatives to strengthen these organizations from the effective utilization of ICT has gained momentum in recent decades (Castells, 1997; Burt \& Taylor, 1999; Kvasny \& Lee, 2003; DCITA, 2005; Kavanaugh et al., 2007). The premise behind such initiatives is that ICT can enable a variety of community organizations to function at lower transaction cost as well as level the playing field between traditional and emerging intermediaries (Bimber, 1998; Edwards, 2006) within environmental governance mechanism.

In the context of community organizations, Pickerill (2001) identifies three particular benefits associated with the effective utilization of ICT; these include increasing outreach and mobilization capabilities, fostering social capital (interaction capabilities), and enhancing the repertoire of environmental protest capabilities. Nevertheless, the issue of benefits associated with ICT is contested in the context of social capital. On the one hand, Putnam (2000) fears that excessive reliance on ICT-mediated interactions (instead of face-to-face interactions) decreases social capital. On the other hand, Wellman et al. (2001) and Hampton (2003) suggest that by providing an additional avenue for interactions, ICT-mediated interactions actually supplement social capital. However, although the potential of ICT to increase the social capital of community organizations has been 
increasingly acknowledged (Gurstein, 2007; Simpson, 2005), only a handful of studies (see Katz et al., 2001; Weare et al., 2005) have empirically explored the ICT-social capital nexus in the context of community organizations. Huysman \& Wulf (2004) consider the lack of interest in the area of 'ICT and social capital' as worrisome in today's increasingly network-centric society. They further assert that with a continued increase in access and availability of ICT, the prospect of ICT furthering social capital is simply too significant to ignore.

This paper responds to this gap by reporting on one aspect of a 2008 survey of environmental community organizations (ECOs) undertaken to develop a broader understanding of the linkages between organizational social capital and information and communication technologies in the Perth region of Western Australia (WA). By exploring the trend of ICT uptake and the association between ICT and social capital, this paper critically engages in the 'ICT and social capital' debate in the context of community organizations. The main research questions underlying this intention are:

- What is the trend of ICT uptake amongst ECOs?

- What is the pattern of ECOs' intra-organizational and inter-organizational interactions?

- Is there an association between the intensity of organizational interactions and ICT uptake?

The paper begins with a brief introduction of ECOs as a distinct subset of civil society, and their role in environmental governance in Perth, followed by an overview of the notion of social capital. Then, the method and findings of the study are described. The paper ends with a conclusion and discussion about the significance of ICT-social capital nexus for environmental governance in Perth.

\section{Environmental Governance and Civil Society in Perth}

The term governance captures a shift from the traditional 'government' structure towards a mechanism in which the 'state' values inputs of the 'private sector' (market) and the 'third sector' (civil society) in the decision-making process. Environmental governance therefore represents formal and informal relationships within and between various actors representing, the state, market, and civil society in order to overcome environmental challenges (Lockwood et al., 2010; Lemos \& Agrawal, 2006). Since environmental crisis is a crisis in governance, environmental strategies in Australia such as the National Landcare Program and the Natural Heritage Trust have extensively relied on environmental community organizations (ECOs) in order to carry out on-ground environmental protection initiatives.

ECOs are autonomous and non-governmental by nature and often identified as a distinct subset of a civil society (Lyons, 2001; Anheier, 2005). Most ECOs in Australia have been established either directly through local community commitment to a particular environmental concern or as a result of encouragement from government agencies to provide more formal representative groups covering catchments and neighbourhoods. The functioning of ECOs is based on the notion and practice of volunteering where community members provide time and energy towards resolving environmental challenges (Dhakal \& Paulin, 2009). The aims of ECOs are often determined by combination of a sense of urgency to stop the development practices that are unsustainable and a perception that government agencies are not moving to correct the situation (Lerner \& Jackson, 1993). There are at least 5,000 ECOs in Australia (Youl et al., 2006) that operate for the public benefit in order to care for, conserve, preserve, maintain and educate the community about the environment. The number of ECOs in the Perth region of WA alone has increased to about 450 in 2004 from around 60 since the mid nineties (Harris \& Scheltema, 1995; SCC, 2004). Needless to say, the position of civil society in environmental governance has strengthened in Perth, at least partially due to the rising number of ECOs.

Since environmental governance is underpinned by the outcomes of relationships (Newig \& Fritsch, 2009), it is often dependent upon strategies to initiate and sustain interactions amongst various actors. Head (2005) suggests that effective environmental governance is dependent upon 
the ability of various actors to maintain a network of relationships facilitated through interactions. ECOs' role in environmental governance can therefore be effective only when these organizations have the necessary support to build and maintain interaction intensive relationships. Hence, the crux of my argument is that environmental governance can benefit from social capital mediated by ICT. It is in this context, the notion of social capital is reviewed next.

\section{Social Capital in Organizations}

The notion of social capital has emerged as one of the dominant topics across disciplines in recent years (Halpern, 2005). The central idea behind the notion is that social ties are valuable, that is, social ties enable various actors to get on with each other and undertake collective action. Nonetheless, social capital remains an ambiguous concept with multiple descriptions and dimensions and some of these ambiguities are rapidly appraised next.

Robert Putnam who is often credited with popularizing social capital in recent decades (Portes, 1998), associates effective governance with social capital and describes it as 'features of social organization, such as trust, norms and networks that can improve the efficiency of society by facilitating coordinated actions' (Putnam, 1995, p. 167). Networks refer to who you know and how well you know them, norms refer to unwritten rules that members of a network abide by, and trust refers to an expectation that others will act for collective interest. Nan Lin is perhaps one of the strongest advocates of the network theory of social capital. Lin (2001) conceptualizes social capital as the resources embedded in a network of social ties and describes it as 'investment in social relations with expected returns in the marketplace' (p. 19). He strongly values the network connections as well as interactions and describes social capital in terms of two interrelated processes: the first pertains to 'resources embedded in social networks accessed and used by actors for actions', while in the second 'actors access social capital through interactions, to promote purposive actions' ( $p$. 25). Lin's emphasis on network interactions also resonates with an observation of Paul Resnick, an advocate of SocioTechnical capital ${ }^{1}$. Resnick (2001) suggests that if two networks exist, one with and one without developed interaction patterns, the former can accomplish its objectives much more effectively and efficiently, even if the two networks are comprised of actors with access to similar resources. Resnick therefore characterizes social capital as 'a residual or side effect of social interactions and enabler of future interactions' (p. 648).

The common thread amongst various descriptions of social capital reviewed above is the significance of interactions in order to maintain network ties. The nature of network ties can be distinguished according to the intensity of interactions; strong ties (frequent interactions) and weak ties (occasional interactions). It was Granovetter (1973) who highlighted the importance of weak ties by suggesting that while strong ties provide more intense social support, weak ties increase access to diverse information, resources and jobs. Building on Granovetter's assertion, several authors have differentiated social capital into three tiers: (a) Bonding; (b) Bridging; and (c) Linking (Gittel \& Vidal, 1998; Putnam, 2000; Woolcock, 2002). Bonding represents horizontal (usually strong) ties between similar actors. Bridging represents vertical (usually weak) ties between different actors. Linking also represents vertical ties but between actors with differing levels of power or status. Since this paper is particularly concerned with community organizations, it is necessary to comprehend social capital in an organizational context. More importantly, clarification is also needed as to whether or not the nature of individual networks and level of social ties can be applied to organizations.

Organizations are social entities created and sustained by human interactions, enabling people to attain collective goals which would not have been possible through individual efforts alone (McAuley et al., 2007). An investigation of the pattern of interactions amongst organizational relationships is one of the primary objectives of organizational research (Pfeffer, 1982). Consequently, exploring the pattern of organizational interactions can provide insights into the process of maintaining social capital within and between organizations because as Cooren (2006) states:

\footnotetext{
${ }^{1}$ Resnick labels ICT-mediated relationships as SocioTechnical capital
} 
If we want to see how organization functions, we need to identify the ways by which things get organized through interactions, and this implies, among other things, that we dwell on the detail of organizational interaction. Even if the organization that I studied may be considered to be, in some respects, heedless, the people working for it (in its name, on its behalf) have to make it work, and one of the means they have at their disposal is to meet regularly to address the problems they can identify and try to solve' (p. 334).

This assertion clearly suggests that the interaction process is what makes the existence of organization possible and enable organizations to act in the manner that they do. As interactions enable the emergence and functioning of organizations, the utility of building and maintaining social capital in ECOs has been increasingly linked with better environmental governance. Few studies have suggested that grassroots organizations that maintain strong internal and external interactions are likely to be successful in creating space for deliberative democratic process and challenging the dominant role of old intermediaries (Severn, 2002; Carr, 2002). Webb and Cary (2005) further assert that community organizations that have been particularly influential in environmental governance are those that are active and have established stronger relationships with the relevant stakeholders such as government agencies and environmental networks. The analysis of patterns of organizational interactions therefore provides an opportunity to understand how organizations make use of the relationships within the networks (Lin, 2001; Resnick, 2001; Bankston III \& Zhou, 2002). This paper therefore proposes social capital in ECOs as a sum of network ties; intraorganizational relationships within ECOs and inter-organizational relationships with other organizations. The intra-organizational component relates to bonding aspects of ties that are built and maintained through the interactions within an ECO (i.e. between leaders and members). The interorganizational component relates to bridging aspects of ties (i.e. with partner organizations and local or regional networks) as well as linking aspects ties (i.e. with peak or umbrella bodies and government agencies).

\section{Methodology}

The Perth region in Western Australia is spread over an area of 770,000 hectares, about half of which is the Perth metropolitan area (the capital city of WA) with a population of approximately 1.5 million. Perth region NRM (Natural Resources Management) is a peak body responsible for managing various environmental issues in the region (PRNRM 2010). As mentioned earlier, it is estimated that about 450 ECOs are active in the region (SCC, 2004). However, a comprehensive list of such organizations do not exist (other than an out-of-date directory published by Swan River Trust in 1996). A conservation directory maintained by Swan Catchment Council (SCC) ${ }^{2}$ listed approximately 150 community organizations in the region and their contact details (retrieved October 10 , 2007 from http://www.swancouncil.org.au). Nonetheless, the list also included organizations that were not necessarily established with environmental motives e.g. churches, community centres, childcare centres and were screened. A total of 116 organizations were considered ECOs and any one leader (chair or vice chair or secretary and so on) of each organization was requested to participate in the survey following the Murdoch University's ethics approval process.

An online survey would have been an obvious choice of data collection in relation to the nature of the study. However, pre-survey consultations revealed that several organizational leaders either lacked skills to complete an online survey or did not have access to ICT. Hence, mail based selfadministered survey was chosen as the preferred method. In order to improve the response rate of mail based survey, highly acclaimed protocol Tailored Design Method (TDM) was utilized to design and disseminate the survey instrument (Dillman, 2000). Building on few extant survey-based studies (ACOSS, 1996; Burt \& Taylor, 1999), a survey was developed to gain a broader understanding of ICT-social capital nexus in ECOs of Perth. The survey titled 'ICT and ECOs' was conducted from June to August in 2008. 83 out of 116 ECOs returned the survey, of which 81 were usable, a re-

\footnotetext{
${ }^{2}$ Swan Catchment Council (SCC) is now known as Perth Region NRM
} 
sponse rate of $68.9 \%$. The response rate was in line with a desirable rate of $50 \%$ or above for the non-profit organizations (Hager et al., 2003). In order to explore the research questions; descriptive statistics, frequencies, cross-tabulations, correlations and tests of statistical significance were carried out using Microsoft Excel and SPSS 16.0 software.

\section{Findings}

Based on the self-reported names, ECOs were categorized into five groups; a) 'catchment' group, b) 'care' group (bushcare, coastcare, landcare, rivercare) c) 'friends' group, d) 'conservation/preservation' group, and e) 'others' (educational centres, foundations, societies). On average, ECOs were established 14.2 years earlier, had 73.3 members, 37.1 volunteers and employed 0.5 staff.

\subsection{Trend of ICT uptake}

The majority (88\%) of responding organizations had access to the Internet and used email. While the lack of access to the Internet amongst $12 \%$ ECOs is clearly an indicator of the binary aspect of the digital divide (haves versus have-nots), there are more complex reasons to why some ECOs do not have access to the Internet. The comments from survey respondents provide some insights. For instance, a coordinator of a 'friends' organization without access to the Internet (ECO \# 36) wrote:

Most interaction is face-to-face. Telephone, fax and personal interactions are the basis of small community based groups.

It is clear from the comment that localized and smaller ECOs generally do not see Internet access as a need. The comment also reflect what van Djik (2005) classifies as 'want-nots' or those who deliberately avoid Internet access. Gandy (2002) argues that data on Internet access alone is insufficient to examine the disparity exist between those who utilize ICT and those who don't. Therefore, a question in the survey also asked, 'Has your organization already adopted or is planning to adopt any of the following ICT?' with options to select; a) hosting a website, b) instant messaging, c) podcasting, d) posting weblogs, e) subscribing to email listservs, and f) videoconferencing. Furthermore, information collected from the responses on modes of interactions (email and mobile phone) were merged with the question above to capture the overall trend of ICT uptake amongst ECOs in the Perth region.

\begin{tabular}{llll}
\hline \multirow{2}{*}{ ICT } & \multicolumn{3}{l}{ Adoption Status } \\
\cline { 2 - 4 } & Already & Planning to & No \\
\hline Email & $71(87.7 \%)$ & n/a & $10(12.3 \%)$ \\
Website & $25(30.9 \%)$ & $10(12.3 \%)$ & $46(56.8 \%)$ \\
Listservs & $20(24.7 \%)$ & $9(11.1 \%)$ & $52(64.2 \%)$ \\
$\begin{array}{l}\text { Mobile/SMS } \\
\text { Instant mes- }\end{array}$ & $18(22.2 \%)$ & n/a & $63(77.8 \%)$ \\
sage & $8(9.9 \%)$ & 0 & $73(90.1 \%)$ \\
$\quad$ Blog & $6(7.4 \%)$ & $12(14.8 \%)$ & $63(77.8 \%)$ \\
\hline $\begin{array}{l}\text { Podcast } \\
\text { Videoconfer- }\end{array}$ & 0 & 0 & 0 \\
ence & 0 & 0 & 0 \\
\hline
\end{tabular}

Table 1: Trend of ICT adoption $(n=81)$

As indicated in Table 1, while nearly $88 \%$ organizations used email, less than one-third $(31 \%)$ of organizations reported hosting websites and less than one-tenth (7\%) of organizations reported posting blogs. The general trend of ICT uptake amongst ECOs in Perth, especially in terms of web- 
sites was surprising as the 2002 CCNR survey had revealed $61 \%$ of community organizations already had websites (Denison, 2003). Interviews and comments on the back of the survey forms in part help explain the general impression of under-utilization of the websites. For instance, a 'wetlands officer' of an 'other' organization (ECO \# 64) commented that the need to constantly update the website as well as cater to online information requests generated a larger workload for an organization run primarily by unpaid volunteers. While it has been argued that putting information on websites will ultimately save time required to organize collective action (Dutton, 1999), the account of the wetlands officer ultimately suggests what Hilty et al. (2006) calls a 'rebound effect' - counterproductive effects of IT (p. 19) as well as the 'productivity paradox' (Macdonald, 2002) - the lack of enhanced productivity despite investment in ICT (p.1).

Several leaders also indicated that the lack of financial means and skills were the primary barriers in managing organizational websites. For example, an executive director of an 'other' organization (ECO \# 80) commented:

We have only been able to establish a web/email presence through sponsorship and grant support. Ongoing technical support is very expensive and is an issue.

Similarly, ECOs that were planning to host websites in the near future were already concerned with their ongoing management. For instance, a president of a 'friends' organization (ECO \# 18) wrote on the back of the survey form that:

\section{We have a website being developed and it's hoped that someone will volunteer to manage it!}

Above feedback suggests that ongoing technical support is far more important than one-off assistance in terms of website creation and management. Interviews with the leaders (ECO \# 4 and ECO \# 66) indicated that websites of their organizations were designed by the younger kin of either one of the volunteers or members. Since organizational leaders do not necessarily have the skills to update and manage the websites, they were more-or-less dependent upon the availability and willingness of those who designed the website. Consequently, a secretary of a 'care' organization (ECO \# 66) felt that blogs were a better alternative to websites particularly for smaller organizations because it is comparatively easy to upload and manage the content.

Table 1 also indicates that none of the ECOs have adopted podcasting or videoconferencing. There are two possible causes behind this. First, since most ECOs are locally operative, there is no actual need for ICT like podcasting or videoconferencing. Second, the lack of reported use may also indicate that the complex and evolving nature of ICT actually prohibit smaller community organizations from adopting newer ICT (Merkel et al., 2007). For instance, not all ECOs were enthusiastic about using even mundane technologies such as email. A coordinator of a 'friends' organization (ECO \# 48) wrote on the back of the survey form that:

Most of our work/time is hands-on, which doesn't leave much time for admin. An advantage of telephone over email, [is that] you actually know whether your message has been received.

The statement of a coordinator suggests an element of resistance towards ICT perhaps due to the lack of ICT skills or know-how. On contrary, a coordinator of a 'friends' organization (ECO \# 38) commented on the reluctance of volunteers to adopt email:

When the group was very active, communication about activities was done by word of mouth, telephone and letterbox drops. The latter were particularly time-consuming. Members were asked to put their email address on the volunteer forms, but only two out of ten did. This wasn't pushed, but it would have been good if it had been adopted. I think they [volunteers] like meeting people and talking in person and do not trust email that much. There is also a concern about being forwarded unwanted emails in the community.

The statement above suggests that some leaders and volunteers affiliated with ECOs do not necessarily have much faith in the potential of email which falls under the category of what van Djik (2005) refers to as 'want-nots' (those who genuinely avoid access for various reasons). The untrustworthiness of the Internet or the fear of email scams resonates with the observations of Se- 
shadri and Carstenson (2007) that email clearly cannot substitute for face-to-face interactions when it comes to building trust or repairing shattered trust.

\subsection{Pattern of organizational interactions}

Pre-survey consultations revealed that most ECOs relied on one active leader who acted as a gatekeeper in exchanging information and maintaining internal as well as external relationships. In order to assess the intensity of organizational interactions as proxy indicators of social capital, a question in the survey asked, 'During the past twelve months, how often did your organization interact with the following?' a) with leaders of your organization, b) with members of your organization, c) with partner organizations, d) with local/regional networks, e) with peak/umbrella bodies, and f) with local/state government agencies. The information on the intensity of interactions was represented on a Likert scale ranging from 0 to $3(0=$ no interaction; $1=$ few times a year; $2=$ few times a month; and $3=$ few times a week). As shown in a mean plot of intensity of interactions (Figure 1), 'catchment' organizations generally reported a higher intensity of intra-organizational and inter-organizational interactions, particularly compared to 'friends' organizations.

The relationship between organizational interactions and types of ECOs were explored using Kruskal-Wallis $^{3}(\mathrm{~K}-\mathrm{W})$ tests. The tests indicated that the intensity of interactions varied significantly between leaders of 'catchment' and 'friends' organizations [K-W $\left.x^{2}(4, n=81)=11.544, p<0.01\right]$ and local/state governmental agencies (the main source of funding) [K-W $\left.x^{2}(4, n=81)=13.559, p<0.01\right]$.

It is likely that the differences between 'friends' and 'catchment' groups comes down to the scope and size of the organizations. Since 'catchment' organizations are generally engaged in a greater number of activities over a larger area, there is a clear need for maintaining frequent interactions between leaders. ECOs that have no immediate need to take action or those engaged in a single environmental issue within a small locality generally have less of a requirement to communicate between members or leaders and coordinate their activities with other organizations. These findings suggest that it is important to explore the pattern of interactions in the context of organizational activities and scope.

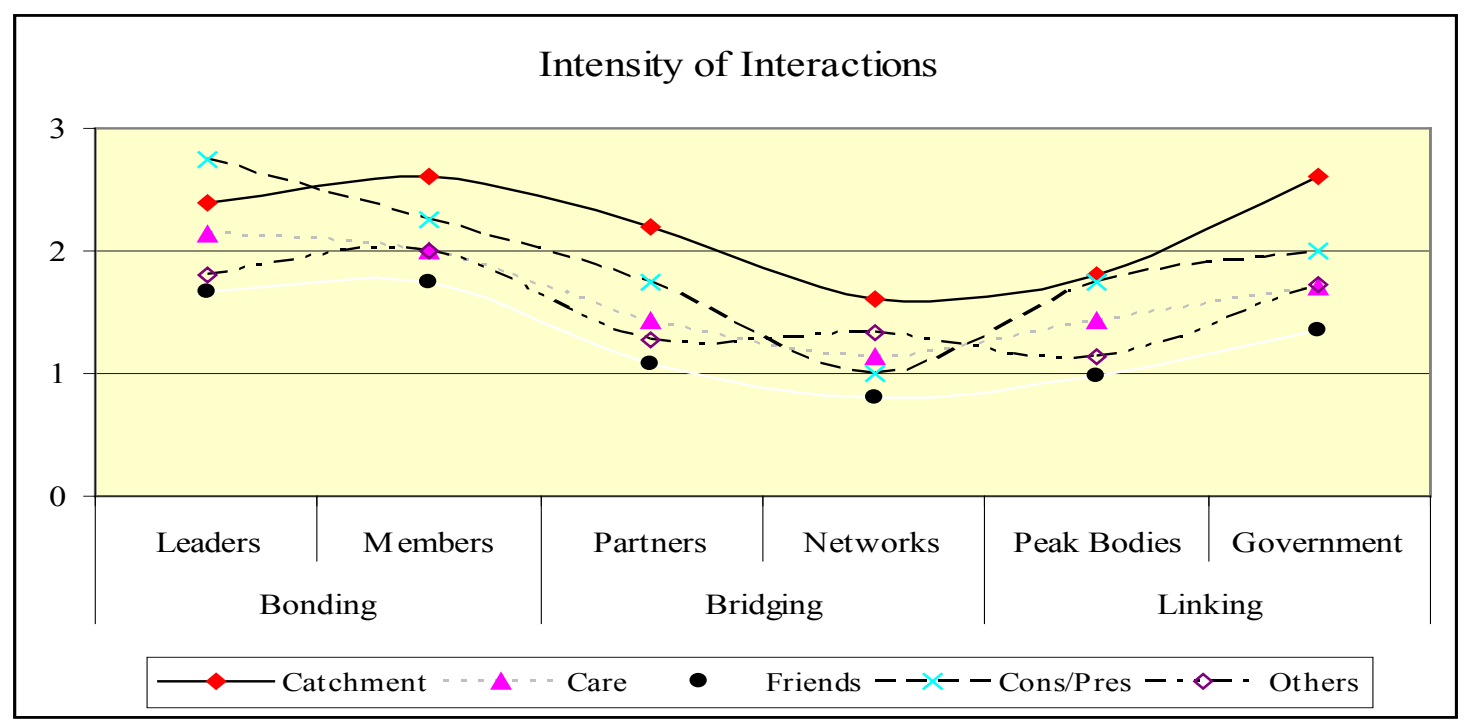

Figure 1: Mean plot of intensity of interactions

\footnotetext{
${ }^{3}$ The Kruskal-Wallis (K-W) test is a non-parametric analysis of variance for comparing the median value of several groups. The K-W test statistics are useful for the ranking the ordinal data (i.e. Likert scale responses) and comparing mean ranks across groups (Agresti \& Finlay, 2009).
} 


\subsection{Mode of interactions}

The survey collected data on five different modes (face-to-face, postal, phone/fax, mobile/SMS, and email) of intra-organizational and inter-organizational interactions. During the data entry process, it was observed that while most respondents reported using multiple modes of interactions, a handful of respondents reported using email as the only mode of interaction. Hence, a separate category of 'only email' was also added for the data analysis.

As Figure 2 shows 'face-to-face' is clearly the preferred mode of intra-organizational interactions and 'email' is the preferred mode of inter-organizational interactions. Moreover, nearly one-quarter of ECOs used 'only email' to interact with local/regional networks and peak/umbrella bodies. However, 'mobile phones/sms' was the least preferred mode of interaction amongst all ECOs in Perth. The results substantiate the findings of other studies (Kellogg, 1999; Kavanaugh et al., 2007) that face-to-face and conventional modes of communication (e.g. telephone, post) are still significant medium for community organizations to interact with their stakeholders. A closer look at the pattern of interactions across different types of ECOs reveals several interesting findings. Firstly, email appears to be the preferred mode for both intra-organizational and inter-organizational interactions for 'catchment' and 'other' organizations. For the rest, email was the preferred mode only for interorganizational interactions. Secondly, none of the 'catchment' organizations used mobile phone/SMS.

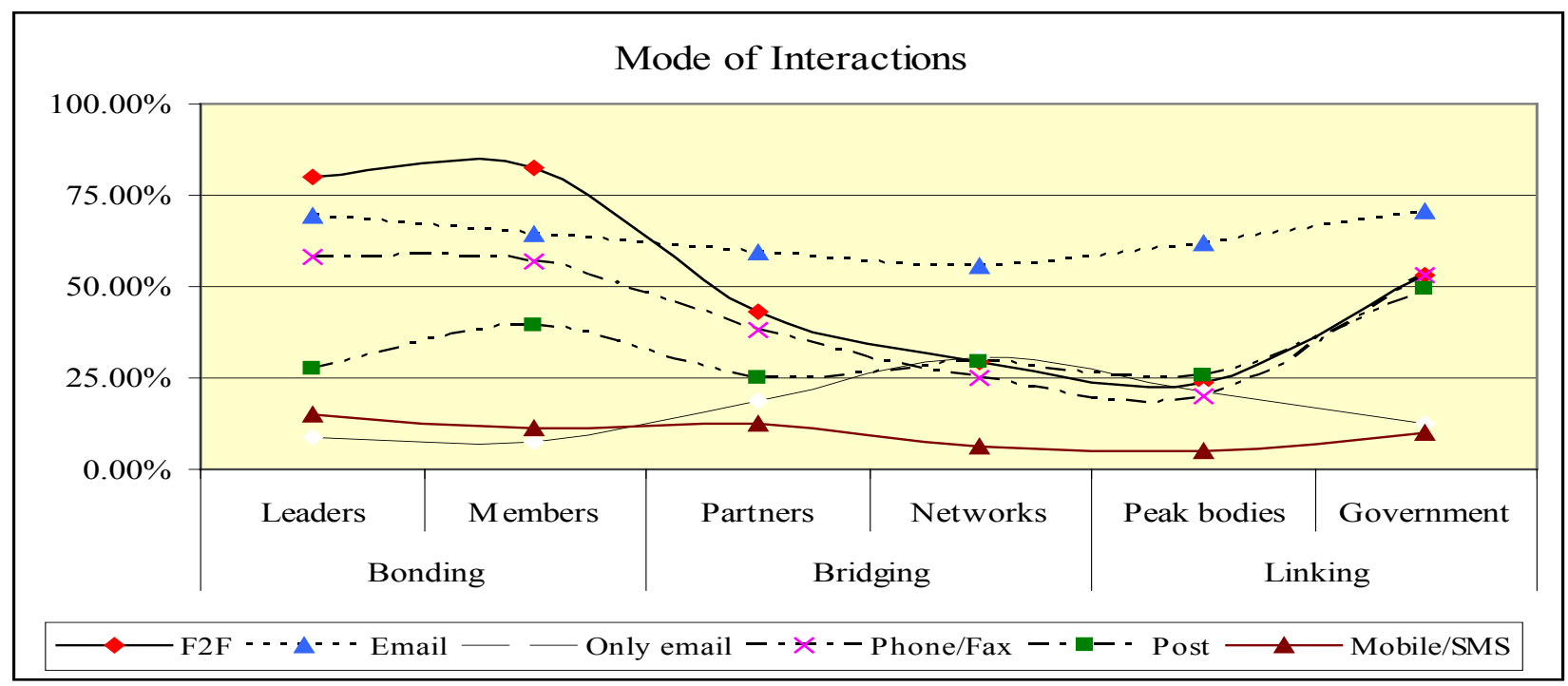

Figure 2: Mode of ECOs' interactions

Although the trend of mobile phone/sms usage was generally very low across organizations, this observation came as particularly surprising. It was expected that there would be at least some degree of mobile communication amongst 'catchment' organizations because of the benefits of coordinating multiple activities of a larger geographical scope. However, email has certainly surpassed telephone as a medium for intra-organizational and inter-organizational interactions. This is consistent with the findings of other studies (Dahlgren, 2000; Katz et al., 2001) that community organizations are gradually expanding their email usage.

\subsection{ICT-social capital nexus}

It is necessary to be mindful that a causal association between ICT and organizational interactions is difficult to establish (Kraut et al. 1998). While one of the ways to establish case-specific causal association is through qualitative observations, in this case the Mann-Whitney $U^{4}$ test was first

\footnotetext{
${ }^{4}$ Mann-Whitney (M-W) $U$ test was chosen to gain case-by-case association between the two. M-W $U$ standing is a non parametric method of comparing mean ranks of ordinal observations (e.g. Likert scale responses) which is the equivalent of
} 
used to explore quantitative association between ICT uptake (email, website, instant messaging, Blogs, listservs, and mobile phone) and the frequency of interactions with the leaders, members, partners, networks, peak bodies and government agencies.

Before proceeding with the test, the responses on ICT uptake was re-coded into two categories 'Yes' and 'No'. For instance, if the respondents had indicated that they were planning to blog in the future, the response was re-coded as 'No'. Table 2 shows several significant differences in the intensity of interactions between adopters versus non-adopters of ICT. It is evident from the M-W $U$ tests that the adopters of websites have significantly greater mean ranks of inter-organizational and intra-organizational interactions than the non-adopters. The other significant differences in interactions between adopters and non adopters of email further confirm the earlier observation that email generally fosters inter-organizational social capital.

\begin{tabular}{|c|c|c|c|c|c|c|c|}
\hline & & \multicolumn{6}{|c|}{ Interactions with: } \\
\hline \multicolumn{2}{|c|}{ Adopted ICT? } & Leaders & Members & Partners & Networks & $\begin{array}{l}\text { Peak } \\
\text { Bodies }\end{array}$ & Government \\
\hline \multirow{4}{*}{ Email } & $\begin{array}{r}\text { Mean Ranks No } \\
(n=10) \\
\text { Mean Ranks Yes }\end{array}$ & 26.55 & 36.45 & 32.3 & 30 & 27 & 31.55 \\
\hline & $\begin{array}{r}\text { Mean Ranks Yes } \\
(n=71)\end{array}$ & 43.04 & 41.64 & 42.23 & 42.55 & 42.97 & 42.33 \\
\hline & $z$ & -2.241 & -0.71 & -1.316 & -1.666 & -2.18 & -1.451 \\
\hline & $p$ & $0.025^{*}$ & 0.478 & 0.188 & $0.096^{\star *}$ & $0.029^{\star}$ & 0.147 \\
\hline \multirow{4}{*}{ Website } & $\begin{array}{r}\text { Mean Ranks No } \\
(n=56) \\
\text { Mean Ranks Yes }\end{array}$ & 33.49 & 37.67 & 37.72 & 37.23 & 35.12 & 37.94 \\
\hline & $(n=25)$ & 57.82 & 48.46 & 48.34 & 49.44 & 54.18 & 47.86 \\
\hline & $z$ & -4.645 & -2.073 & -1.977 & -2.275 & -3.653 & -1.876 \\
\hline & $p$ & $0.000^{\star}$ & $0.038^{\star}$ & $0.048^{\star}$ & $0.023^{\star}$ & $0.000^{\star}$ & $0.061^{\star \star}$ \\
\hline \multirow{4}{*}{ Listservs } & $\begin{array}{r}\text { Mean Ranks No } \\
(n=61) \\
\text { Mean Ranks Yes }\end{array}$ & 39.4 & 39.35 & 41.03 & 41.2 & 38.8 & 39.16 \\
\hline & $(n=20)$ & 45.88 & 46.03 & 40.9 & 40.38 & 47.7 & 46.6 \\
\hline & $z$ & -1.154 & -1.197 & -0.023 & -0.144 & -1.591 & -1.312 \\
\hline & $p$ & 0.249 & 0.231 & 0.982 & 0.885 & 0.112 & 0.189 \\
\hline \multirow[t]{4}{*}{ Mobile/sms } & $\begin{array}{r}\text { Mean Ranks No } \\
(n=63) \\
\text { Mean Ranks Yes } \\
(n=18)\end{array}$ & 37.08 & 38.81 & 39.21 & 36.37 & 36.84 & 37.84 \\
\hline & $(n=18)$ & 54.72 & 48.67 & 47.28 & 57.19 & 48.56 & 52.06 \\
\hline & $z$ & -3.032 & -1.704 & -1.356 & -3.493 & -1.675 & -2.418 \\
\hline & $p$ & $0.002^{\star}$ & $0.088^{\star \star}$ & 0.176 & $0.000^{*}$ & $0.094^{\star \star}$ & $0.016^{\star}$ \\
\hline \multirow{4}{*}{$\begin{array}{r}\text { Instant } \\
\text { Message }\end{array}$} & $\begin{array}{r}\text { Mean Ranks No } \\
(n=73) \\
\text { Mean Ranks Yes }\end{array}$ & 40.15 & 39.9 & 40.38 & 40.65 & 39.18 & 40.16 \\
\hline & $(n=8)$ & 48.5 & 51.06 & 46.69 & 44.19 & 57.63 & 48.63 \\
\hline & $z$ & -1.026 & -1.385 & -0.759 & -0.426 & -2.283 & -1.032 \\
\hline & $p$ & 0.305 & 0.166 & 0.448 & 0.67 & $0.022^{*}$ & 0.302 \\
\hline \multirow[t]{4}{*}{ Blog } & $\begin{array}{r}\text { Mean Ranks No } \\
(n=75) \\
\text { Mean Ranks Yes } \\
(n=6)\end{array}$ & 40.27 & 39.99 & 40.13 & 40.95 & 39.36 & 40.31 \\
\hline & $(n=6)$ & 50.17 & 53.67 & 51.83 & 41.5 & 61.5 & 49.67 \\
\hline & $z$ & -1.072 & -1.49 & -1.235 & -0.067 & -2.405 & -1.003 \\
\hline & $p$ & 0.284 & 0.136 & 0.217 & 0.967 & $0.016^{*}$ & 0.316 \\
\hline
\end{tabular}

Table 2: Mann-Whitney $U$ tests between ICTs uptake vs. mean ranks of interactions

the parametric student t-test. The M-W test ranks ordinal observations from low to high and is used to determine if two categories of ordinal observations have the same median or not. Instead of a t value in the student $t$-test, $M-W$ relies on $z$ value (Williams \& Monge, 2001). 
Interestingly no significant differences in mean ranks of interactions between the adopters and nonadopters of listservs were detected. However, since organizations with websites also have a higher intensity of inter-organizational as well as intra-organizational interactions, it is possible that ICT tend to benefit organizations already with high levels of social capital. This finding is not surprising as other studies have raised the concern that ICT initiatives strengthen those intermediaries already rich in social capital rather than serving the needs of actors with less social capital (ESRC, 2006).

Qualitative accounts provide further insights into the differences in ICT-social capital nexus. For instance, a coordinator of a 'catchment' organization (ECO \# 1) in an email wrote:

You asked how I hear about Grants. One way is through emails like the one below which is sent out weekly by an organization called the Environmental Educators Network. I'm not sure how people hear about the email and get included, but once you're on, it's a useful source of information about jobs, grants, training courses and activities.

In addition, a convenor of a 'friends' organization (ECO \# 20) commented that:

You have left out questions about interests/aptitudes - we use ICT because of our own interest and curiosity about whether they will help us in our work. We use Google to document our work and record what needs to be done. My conclusion is that ICT doesn't help much in recruiting volunteers or retaining members but it does help us to work together with the local government and to ensure transparency. We need to know how their money is spent. One technology very useful to environmental groups [like ours] is Google maps - [which] makes aerial maps much more accessible and affordable.

While these two accounts of organizational leaders clearly indicate benefits of ICT-social capital nexus, an 'other' organisation (ECO \# 81) further demonstrates evidence of the significance of ICT mediated social capital in environmental governance in Perth. Through its website, this organization allows interested visitors to send an online petition directly to the WA Premier requesting to cancel the proposed highway construction over the ecologically significant wetlands. The persistent 'online' activism of the organization has been able to spark an 'offline' collective action for several years in order to pressure the government. However, not all organizational leaders were enthusiastic about the benefits associated with ICT. For instance, a president of an 'other' organization (ECO \# 59) commented (in bullet points) that:

- We have very active older/senior members + [sic] volunteers who don't use email/websites. We ring them or visit them.

- We try to reduce the number of emails + [sic] length of e-mails otherwise it just becomes 'noise'.

- People need to be able to 'do' all the ICT stuff to make it effective without overloading, we are all volunteers, many involved elsewhere.

Echoing the previous respondent, a chairperson of an 'other' organization (ECO \# 60) wrote on the back of the survey that:

One of the main concerns for community organizations like ours is that government departments now only interact with us via Internet and also this is the only way to get reports etc. These can often be very large files. There is a big cost in dollars and time as well as printing if these reports are to be scanned or read. This is becoming a major concern.

These two accounts once again indicate that factors like time, age (not only of the leaders but also of the volunteers and members), information overload ('noise'), and cost might have adversely affected the benefits associated with the ICT-social capital nexus for some ECOs. 


\section{Conclusion and Discussion}

The objective of this paper was to explore the trend of ICT uptake, pattern of organizational interactions, and ICT-social capital nexus amongst ECOs in the Perth region of WA. While most ECOs have access to the Internet and use email, less than one-third have websites and less than onetenth post blogs. These findings are consistent with the observations of Kirschenbaum \& Kunamneni (2002) that community organizations in general have struggled to find ways to utilize ICT as a tool to advance their missions. Although community organizations including ECOs have traditionally invested fewer resources in ICT, recent trend, especially in the developed countries, indicate that these organizations are better positioning themselves to benefit from ICT (Finn et al., 2004). The low uptake of ICT can generally be considered 'disappointing' when compared to the 2002 survey of community organizations in Australia (Denison, 2003) and point to organizational divide the lack of ICTs capability of community organizations (Manzo \& Pitkin, 2007; McNutt, 2008; Dhakal, 2009) and once again suggest that complex and evolving nature of ICTs may not always be the tools of empowerment (Merkel et al., 2007) for smaller community organizations such as ECOs. It is likely the case that the lack of ICT uptake is an indication of a greater predominance of importance placed upon face-to-face interactions more than the digital divide itself (Kavanaugh et al., 2007). In other words, low ICT uptake amongst ECOs in Perth may not necessarily be perceived as binary understanding of the digital divide but in terms of preferred mode of interactions. There might be two other reasons behind the under-utilization of ICT amongst ECOs. First, ICT has not been the main organizational priority of most ECOs surveyed. Unlike the findings of Williams (2005), it is possible that ECOs either do not make use of their social capital to build ICT competence, or the organizations that ECOs maintain relationships with are not the kind that can help build ICT capability. Second, qualitative observations suggest that some ECOs rely on relatives of the leaders, members or volunteers for trouble-shooting or setting up websites or blogs. Since the trend of ICT uptake amongst ECOs in the Perth region is more-or-less limited to email usage; it is plausible to assume that organizations often depend on others for solving ICT related problems instead of building their own ICT capabilities because the leaders of ECOs are concerned about 'rebound effect' (Hilty et al., 2006) or 'productivity paradox' (Macdonald, 2002).

The primary intent of the paper was to assess whether or not ICT uptake fostered social capital of ECOs, and if so, to what extent ICT-social capital nexus is significant in environmental governance. The findings clearly suggest that ECOs that have adopted ICT are in a better position to supplement organizational social capital. Overall, the email usage seemed to foster inter-organizational interactions more than intra-organizational interactions. The data analysis also suggest that although email is one of several modes of interaction that are available to ECOs (Katz \& Rice, 2002), these organizations benefited from what email has to offer, both in terms of intra-organizational interactions and coordinating between leaders members and intra-organizational interactions or networking with other organizations. The preferences of those ECOs who use ICT to foster interactions support the view of Wellman et al. (2001) that when ICT is used to interact and coordinate with organizations, both internally and externally, then it is a tool for building and maintaining social capital. However, ECOs with websites having higher 'inter' as well as 'intra' organizational interactions also suggest that ICT tend to benefit organizations already with higher social capital. Depending on the scope of organizational objectives and activities, it might well be the case that not all ECOs in Perth need to adopt ICT. Yet, as ICT become increasingly ubiquitous in an organizational context, ECOs that are either not able to or not willing to keep up with the ICT trend could be at risk (if not already) of further digital disadvantage.

It is not to suggest here that ECOs that have not adopted ICT cannot be enabled; instead, the role of civil society in environmental governance is likely to be enhanced from ECOs that have adopted ICT for two reasons. First, van Bueren et al. (2003) argue that ineffective environmental governance is largely a reflection on the lack of interactions amongst stakeholders. As observed amongst ECOs in Perth, ICT as supplementary avenue of interactions certainly has value in strengthening civil society's volume of interactions in environmental governance. Second, the theoretical conjecture that links social capital and environmental governance proposes intra- 
organizational and inter-organizational relationships of ECOs as a necessary ingredient of successful environmental outcomes (Pretty \& Ward, 2001). However, one of the significant constraints associated with social capital is that it is dependent upon continued renewal of acquaintances (i.e. interactions intensive) which generally resources-stricken community organizations find it difficult to sustain. Since interaction is a necessary condition for building social capital, the findings clearly indicates that ICT enables intra-organizational as well as inter-organizational interactions amongst ECOs.

There is a general desire to provide clarity in terms of the contributions ICT can make to the broader well-being of the society. As much as the potential of ICT has been discussed in the context of the role civil society in environmental governance, ECOs in general have slipped under the radar of ICT oriented-practices and theoretical approaches. While ICT are inanimate objects (Brignall III \& van Valey, 2005), the associated merits or demerits will ultimately depend on how the users (i.e. ECOs in this case) make use of them. In this context, purely techno-centric solutions to societal problems are misleading and the findings of this paper rejects technological deterministic stances on ICT as a 'must have' tool for 'every' community organization (Mclver, 2002). The general conclusion of the paper is consistent with the networked society stance (Castells, 2000; Mol, 2006) which relates the ICT uptake with a thriving civil society (Floridi, 2001, Hacker et al., 2009). The research findings show environmental governance can benefit from the role ICT plays in fostering social capital in ECOs. Future environmental strategies in Perth that rely on ECOs to carry out on-the-ground environmental aspirations may benefit by harnessing the ICT-social capital nexus in civil society.

\section{References}

ACOSS (1996). Electronic communication and the community sector final report: ACOSS paper no. 81. Sydney: Australian Council of Social Service (ACOSS).

Agresti, A., \& Finlay, B. (2009). Statistical methods for the social sciences. Upper Saddle River: Prentice Hall.

Anheier, H. K. (2005). Nonprofit organizations theory, management, policy. London: Routledge.

Bankston III, C. L., \& Zhou, M. (2002). Social capital as process: The meanings and problems of a theoretical metaphor? Sociological Inquiry, 72(2), 285-317.

Bimber, B. (1998). The Internet and political transformation: populism, community and accelerated pluralism. Polity, 31(1), 133-149.

Brignall III, T. W., \& Valey, T. V. (2005). The impact of Internet communications on social interaction. Sociological Spectrum, 25, 335-348.

Burt, E., \& Taylor, J. (1999). Information and communication technologies: Reshaping the voluntary sector in the information age? Glasgow: Centre for the Study of Telematics and Governance [CSTAG], Glasgow Caledonian University. Retrieved from http://virtualsociety.sbs.ox.ac.uk/reports/voluntarymain.htm\#Top

Carr, A. (2002). Grass roots and green tape principles and practices of environmental stewardship. Sydney, NSW: The Federation Press.

Castells, M. (1997). The power of identity: The information age: Economy, society and culture: Volume I. Oxford: Blackwell.

Castells, M. (2000). The rise of the networked society: The information age: Economy, society and culture: Volume I. Oxford: Blackwell.

Cooren, F. (2006). Arguments for the in-depth study of organizational interactions. Management Communication Quarterly, 19(3), 327-340.

Dahlgren, P. (2000). The Internet and the democratization of civic culture. Political Communication, 17(4), 335-340.

Department of Communications, Information Technology and the Arts of the Australian Government (DCITA) (2005). Information and communications technology transforming the nonprofit sector: A discussion paper. Canberra: Commonwealth of Australia. Retrieved from http://www.archive.dbcde.gov.au/_data/assets/pdf_file/0018/23751/ICT_Transforming_the_Non-profit_Sector.pdf

Denison, T. (2003). Community sector organizations: patterns of Internet uptake and use. Paper presented at $2 n d$ IRS International Conference at Gippsland Monash University, 13-14 November 2003. Retrieved from http://ccnr.net/system/files/Tom+EGovernance-new.doc 
Dhakal, S. P. (2008). Do ICTs facilitate social capital of community based environmental nonprofit organisations? In B. Adkins \& M. Docherty (Eds.) Proceedings of the 2008 Australasian Symposium on Interaction Design ASID 08: Innovation in Interaction Design (pp. 1-6). Brisbane: Queensland University of Technology.

Dhakal, S. P. (2009). The digital divide and gender: A survey of environmental community organization's leaders in Perth, Western Australia. Journal of Community Informatics, 5(3-4). Retrieved from www.cijournal.net/index.php/ciej/article/view/524/511

Dhakal, S. P., Paulin, S. (2009). Social capital and sustainability of urban environmental groups in Perth. In Maginn, P. et al (Eds.), Proceedings of the $4^{\text {th }}$ National Conference on the State of Australian Cities (SOAC): City growth, sustainability, vitality and vulnerability, 24-26 November 2009. Nedlands, WA: University of Western Australia.

Dillman, D. A. (2000). Mail and internet surveys-the tailored design method. New York, NY: John Wiley \& Sons.

Dunn, A. (2011). Unplugging a nation: State media strategy during Egypt's January 25 uprising. The Fletcher Forum of World Affairs. 35(2), 15-24.

Dutton, W. (1999). Society on the line: Information politics in the digital age. New York, NY: Oxford University Press.

Edwards, A. (2006). ICT strategies of democratic intermediaries: A view on the political system in the digital age. Information Polity, 11, 163-176.

Economic and Social Research Council (ESRC) (2006). ICT social capital and voluntary action. In ESRC (Ed.), The Economic and Social Research Council (ESRC) Seminar Series: Mapping the public policy landscape. Retrieved from http://www.ncvo-

vol.org.uk/sites/default/files/UploadedFiles/NCVO/Publications/Publications_Catalogue/Sector_Research/ICT_social_ capital_voluntary_action.pdf

Finn, S., \& Maher, J. K., \& Forster, J. (2006). Indicators of Information and Communication Technology adoption in the nonprofit sector changes between 2000 and 2004. Nonprofit Management \& Leadership, 16(3), 277-295.

Floridi, L. (2001). Information ethics: An environmental approach to digital divide. Philosophy in the Contemporary World, 9(1). Retrieved from http://www.philosophyofinformation.net/publications/pdf/ieeadd.pdf

Gandy, O. (2002). The real digital divide: Citizens versus consumers. In L. Lievrouw \& S. Livingstone (Eds.), Handbook of new media: Social shaping and consequences of ICTs (pp. 448-460). Thousand Oaks, CA: Sage.

Gittel, R. J., \& Vidal, A. (1998). Community organizing: Building social capital as a development strategy. Thousands Oak: Sage.

Granovetter, M. (1973). The strength of weak ties: A network theory revisited. Sociological Theory, 1, 201-233.

Gurstein, M. (2007). What is community informatics (and why does it matter?). Milan: Polimetrica.

Hacker, K. L., Mason, S. M., \& Morgan, E. L. (2009). Digital disempowerment in a network society. International Journal of Electronic Government Research, 5(2), 57-71.

Hager, M. A., Wilson, S., Pollak, T. H., \& Rooney, P.M. (2003). Response rates for mail surveys of nonprofit organizations: A review and empirical test. Nonprofit and Voluntary Sector Quarterly, 32(2), 252-267.

Halpern, D. (2005). Social capital. Cambridge, UK: Polity Press.

Hampton, K. N. (2003). Grieving for a lost network: Collective action in a wired suburb. The Information Society, 19, 417428.

Harris, J., \& Scheltema, M. (1995). Introduction. In M. Scheltema \& J. Harris (Eds.), Managing Perth's Bushlands and how to manage them (pp. 3-6). Perth: Greening Western Australia.

Hawken, P. (2007). Blessed unrest: How the largest movement in the world came into being and why no one saw it coming. New York, NY: Penguin Books.

Head, B. (2005). Participation or co-governance? Challenges for regional natural resources management. In R. Eversole \& J. Martin (Eds.), Participation and governance in regional development global trends in an Australian context (pp. 137-154). Hampshire: Ashgate Publishing Ltd.

Hilty, L. M., Kohler, A., Scheele, F. von, Zah, R., \& Ruddy, T. (2006). Rebound effects of progress in information technology. Poiesis Prax, 4, 19-38.

Huysman, M., \& Wulf, V. (2004). Social capital and information technology. London: MIT Press.

Katz, J. E., \& Rice, R. E. (2002). Social consequences of Internet use Access involvement and interaction. London: MIT Press.

Katz, J. E., Rice, R. E., \& Aspden, P. (2001). The Internet, 1995-2000 access, civic involvement, and social interaction. American Behavioral Scientist, 45(3), 405-419.

Kavanaugh, A. L., Zin, T. T., Rosson, M. B., Carroll, J. M., Schimtz, J., \& Joon Kim, B. (2007). Local groups online: Political learning and participation. Computer Supported Cooperative Work, 16, 375-395.

Kellogg, W. A. (1999). Community-based organizations and neighbourhood environmental problem solving: A framework for adoption of information technologies. Journal of Environmental Planning and Management, 42(4), 445-469.

Kirshenbaum, J., \& Kunamneni, R. (2002). The organizational divide. In L. J. Servon (Ed.), Bridging the digital divide technology, community and public policy (pp. 177-198). London: Blackwell Publishing. 
Kraut R. E., Mukhopadhyay, T., Szczypula, J., Kiesler, S., \& Sherlis, B. (1998). Internet paradox: A social technology that reduces social involvement and psychological well-being? American Psychologist, 53(9), 1017-1031.

Kvasny, L. , \& Lee, R. L. (2003). Towards a framework to enhance the technology capacity of community-based organizations in urban contexts. In Proceedings of Ninth Americas Conference on Information Systems (pp. 1574-1579).

Lemos, M. C., \& Agrawal, A. (2006). Environmental governance. Annual Review of Environmental Resources, 31, $297-325$.

Lerner, S., \& Jackson, J. (1993). Reflecting on what we have learned. In. S. Lerner (Ed.) Environmental stewardship studies in active earthkeeping (pp. 385-397). Waterloo: Department of Geography, University of Waterloo.

Lin, N. (2001). Social Capital: A theory of social structure and action. London: Cambridge University Press.

Lockwood, M., Davidson, J., Curtis, A., Stratford, E., \& Griffith, R. (2010). Governance principles for natural resources management. Society and Natural Resources, 23, 986-1001.

Lyons, M. (2001). Third sector: the contribution of non-profit and cooperative enterprises in Australia. Sydney: Allen \& Unwin.

Macdonald, S. (2002). The IT productivity paradox revisited: Technological determinism masked by management method? International Journal of Information Technology and Management, 1(1), 1-29.

Manzo, P., \& Pitkin, B. (2007). Barriers to information technology usage in the nonprofit sector. In M. Cortes \& K. M. Rafter (Eds.), Nonprofits and technology emerging research for usable knowledge (pp. 51- 67). Chicago: Lyceum Books.

McAuley, J., Duberly, J., \& Johnson, P. (2007). Organization theory: Challenges and perspectives. Essex: Pearson Education.

Mclver, W. (2003). A Community informatics for the information society. In S. O'Siochru \& B. Girard (Eds.), Communicating in the information society (pp. 33-64). Geneva, CH: United Nations Research Institute for Social Development.

McNutt, J. (2008). Advocacy organizations and the organizational digital divide. Currents: New Scholarship in the Human Services, 7(2), 1-13.

Merkel, C., Farooq, U. L., Xiao, C., Ganoe, M., Rosson, B., \& Caroll, J. M. (2007). Managing technology use and learning in nonprofit community organizations: Methodological challenges and opportunities. Paper presented at CHIMIT'07, 3031 March 2007, Cambridge, USA.

$\mathrm{Mol}$, A. P. J. (2006). Environmental governance in the information age: The emergence of informational governance. Environment and Planning C: Government and Policy, 24, 497-514.

Newig, J., \& Fritsch, O (2009). Environmental governance: participatory, multi-level-and effective? Environmental Policy and Governance, 19, 197-214.

Pfeffer, J. (1982). Organizations and organization theory. Marshfield: Pitman Publishing.

Pickerill, J. (2001). Weaving a green web Environmental protest and computer-mediated communication in Britain. In F. Webster (Ed.), Culture and politics in the information age: A new politics? (pp. 142-166). London: Routledge.

Portes, A. (1998). Social capital: Its origins and applications in modern sociology. Annual Review of Sociology, 22, 1-24.

Pretty, J., \& Ward, H. (2001). Social capital and the environment. World Development, 29(2), 209-227.

PRNRM (2010). Perth Region Natural Resources Management (PRNRM). Retrieved from http://www. perthregionnrm.com Putnam, R. (2000). Bowling alone the collapse and revival of American community. New York, NY: Simon and Schuster.

Putnam, R. D. (1995). Tuning in, tuning out: The strange disappearance of social capital in America. Political Science and Politics, 28(4), 664-683.

Resnick, P. (2002). Beyond bowling together: Sociotechnical capital. In J. M. Carroll (Ed.), HCl in the new millennium (pp. 247-272). Boston: Addison-Wesley.

Ritter, D. P., \& Trechsel, A. H. (2011). Revolutionary cells: On the role of texts, tweets, and status updates in nonviolent revolutions. Paper presented at the 'Internet, Voting and Democracy' Conference, Laguna Beach, CA, 14-15 May 2011.

SCC (2004). The swan region natural resources management strategy. Midland, WA: Swan Catchment Council (SCC).

Seshadri, S., \& Carstenson, L. (2007). The perils of email communication in non-profits. Nonprofit Management \& Leadership, 18(1), 77-99.

Severn, R. C. (2002). A gentler, more intimate, more accessible brand of heroism: A study of how the leaders of grassroots environmental activism create space for deliberative democratic process. (Unpublished doctoral dissertation). Murdoch, WA: Murdoch University.

Simpson, L. (2005). Community informatics and sustainability: why social capital matters? The Journal of Community Informatics, 1(2), 103-120.

van Bueren, E.M., Klijn, E. H., \& Koppenjan, J. F. M. (2003). Dealing with wicked problems in networks: Analyzing an environmental debate from a network perspective. Journal of Public Administration Research Theory, 13, 193-212.

van Dijk, J. (2005). The deepening divide inequality in the information society. Thousand Oaks: Sage.

Weare, C., Loges, W.E., \& Oztas, N. (2005). Does the Internet enhance the capacity of community associations? In P. van den Besselaar, G. De Michelis, J. Preece, \& C. Simone (Eds.), Communities and Technologies (pp. 1-18). Netherlands: Springer. 
Webb, T., \& Cary, J. (2005). Social capital and natural resource management: An application to landcare. Rural Society, 15(2), 119-131.

Wellman, B., Haase, A. Q., White, J., \& Hampton, K. (2001). Does the Internet increase, decrease or supplement social capital? Social networks, participation and community commitment. American Behavioral Scientist, 45(3), 436-465.

Williams, F., \& Monge, P. (2001). Reasoning with statistics: How to read quantitative research. Belmont: Thomson Wadsworth.

Williams, K. H. (2005). Social networks, social capital, and the use of information and communications technology in socially excluded communities: a study of community groups in Manchester, England. (Unpublished doctoral dissertation). Ann Arbor, Ml: University of Michigan.

Woolcock, M. (2002). Social capital in theory and practice: Reducing poverty by building partnerships between states, markets and civil society. In UNESCO (Ed.), Social capital and poverty reduction: Which role for the civil society organizations and the state? (pp. 20-44). Paris: United Nations Educational, Scientific and Cultural Organization (UNESCO).

Youl, R., Marriott, S., \& Nabben., T. (2006). Landcare in Australia founded in local action. Wallington, Victoria: Secretariat for International Landcare Inc and Rob Youl Consulting.

\section{About the Author}

Subas P. Dhakal

Subas P. Dhakal completed (in 2010) his PhD from Murdoch University in the area of 'Sustainability and Technology Policy'. His research/teaching interests include; civil society, ICT, social capital, and sustainable development. 